\title{
Androgens and masculinization of genitalia in the spotted hyaena (Crocuta crocuta). 2. Effects of prenatal anti-androgens
}

\author{
C. M. Drea ${ }^{1}$, M. L. Weldele ${ }^{1}$, N. G. Forger ${ }^{2}$, E. M. Coscia ${ }^{1}$, \\ L. G. Frank ${ }^{1}$, P. Licht ${ }^{3}$ and S. E. Glickman ${ }^{1}$ \\ ${ }^{1}$ Department of Psychology, University of California, Berkeley, CA 94720; ${ }^{2}$ Department of Psychology, \\ University of Massachusetts, Amherst, MA 01003; and ${ }^{3}$ Department of Integrative Biology, University of \\ California, Berkeley, CA 94720, USA
}

\begin{abstract}
Pregnant spotted hyaenas were treated with anti-androgens to interfere with the unusually masculine 'phallic' development that characterizes females of this species. The effects on genital morphology and plasma androgen concentrations of infants were studied during the first 6 months of life. Although there were consistent 'feminizing' effects of prenatal anti-androgen treatment on genital morphology in both sexes, such exposure did not produce males with extreme hypospadia, as it does in other species, nor did it produce females with a 'typical' mammalian clitoris and external vagina. 'Feminization' of males resulted in a penis with the morphological features of the hyaena clitoris, and 'feminization' of females exaggerated the sex differences that are typical of this species. The effects of treatment were present at birth and persisted for at least 6 months. Treatment of pregnant females with flutamide and finasteride also markedly reduced circulating concentrations of testosterone and dihydrotestosterone in maternal plasma during pregnancy. Plasma $\Delta^{4}$-androstenedione was reduced in the female, but not the male, infants of treated mothers, consistent with an epigenetic hypothesis previously advanced to explain hormonal 'masculinization' of females. The present 'feminizing' effects of prenatal anti-androgen treatment are consistent with contemporary understanding of sexual differentiation, which accounts for morphological variation between the sexes in terms of steroids. However, current theory does not account for the basic genital structure of females and the present data suggest that development of the male penis and scrotum, and the female clitoris and pseudoscrotum, in spotted hyaenas may involve both androgen-dependent and androgen-independent components.
\end{abstract}

\section{Introduction}

Female spotted hyaenas have the most 'masculinized' external genitalia of any female mammal. The vagina is fused to form a pseudoscrotum and the clitoris, or pseudopenis, is elongated and fully erectile, traversed to its tip by a central urogenital canal through which the female urinates, copulates, and gives birth (Watson, 1877). On close inspection, it is apparent that there are substantial differences between the female clitoris and the male penis of the spotted hyaena. The clitoris is shorter and thicker than the penis (Neaves et al., 1980; Forger et al., 1996) and the urogenital meatus at the tip of the clitoral glans is larger and more elastic than the opening at the tip of the glans penis, which presumably facilitates reception of the male during copulation and delivery of young (Glickman et al., 1992a). Finally, when erect, the glans penis presents an angular appearance at its distal end, whereas the glans clitoridis is more rounded (Frank et al., 1990). Thus, despite a long history of

Received 14 August 1997 confusion about external sexing, the genitalia of the two sexes can be distinguished easily by a trained observer.

The masculinized external genitalia of female spotted hyaenas have generally been attributed to the organizational effects of androgens acting during fetal life and the activational effects of gonadal steroids operating during postnatal life (Matthews, 1939; Glickman et al., 1992b). $\Delta^{4}$-Androstenedione (androst-4-ene-3,17,dione) of ovarian origin is the primary circulating androgen in female spotted hyaenas throughout postnatal life (Lindeque et al., 1986; Glickman et al., 1987, 1992a). Placental conversion of maternal $\Delta^{4}$-androstenedione to testosterone is the probable source of testosterone for the developing female fetus (Licht et al., 1992; Yalcinkaya et al., 1993). It has been demonstrated that this conversion of $\Delta^{4}$-androstenedione to testosterone is in place during sexual differentiation of the fetus and that radiolabelled maternal $\Delta^{4}$-androstenedione is transferred to the fetus as testosterone (Licht et al., 1998).

Thus far, there have been no direct tests of androgenic influence on the developing genitalia of female hyaenas, either 
during fetal life or in association with puberty. The present study was undertaken to test the actual role of androgens in regulating the formation and growth of a penile clitoris in the female of this species. In addition, since development of the penis during fetal life and pubertal growth of the penis during postnatal life are generally attributed to androgenic stimulation, the role of androgens in the formation and development of the penis in male hyaenas was also examined. Data regarding androgenic influence are presented from two different life stages: the fetal stage (present study) and the pubertal stage (Glickman et al., 1998). In the present study, antiandrogens were administered to pregnant hyaenas and the effects on their offspring were examined to determine whether androgens are responsible for the development of the hyaena clitoris and fusion of the vaginal labia during fetal life. Because of the unusual genital morphology of female spotted hyaenas, stillbirths are common during first deliveries (Frank et al., 1995), so for genital measurements, the infant subject pool included live cubs as well as stillborn neonates.

With regard to genital development during fetal life, if it is assumed that the differences in appearance of the female and male external genitalia described above are the result of the higher concentrations of testosterone circulating in males (from the fetal testes), provision of anti-androgens during the critical stages of development should result in males and females converging on a single anatomical profile. For example, male rodents and dogs exposed to anti-androgens during fetal life develop a blind vaginal pouch, rather than a scrotum, and a penis that is much reduced in size, with the urethra opening at the base of the organ rather than at the tip (hypospadia: Neri et al., 1972). Therefore, if development of the 'masculinized' genitalia of female spotted hyaenas is similarly dependent on the actions of placental androgens, interfering with the action of testosterone at androgen receptors should result in both male and female hyaenas displaying the more typical configuration of female mammals. Both sexes would show a marked reduction in penile-clitoral size, with the organ no longer traversed by the urethra to the tip, and there would be an external vaginal opening instead of the scrotum-pseudoscrotum.

There is an alternative possibility. Arnold (1996) has recently noted that convergent evidence from mammals and birds suggests direct genetic effects on sexually dimorphic systems. For example, the formation and development of the female marsupial pouch or the male scrotum from abdominal tissue are the result of genetically controlled processes, independent of androgenic influence (Renfree and Short, 1988). These observations provide a precedent for the presence of elaborate, female-specific, external reproductive structures that differ from those of the male, without the intervention of androgens. Thus, there are at least two alternative, though not necessarily mutually exclusive, hypotheses that could explain the formation of the spotted hyaena clitoris; the first involves an androgen-dependent mechanism and the second an androgen-independent mechanism.

Interfering with an androgen-dependent mechanism would probably result in the convergence of external genital morphology on the typical female mammalian form (that is, with an external vagina or blind vaginal pouch, and a clitoris of reduced size, no longer traversed by a central urogenital canal). If an androgen-independent mechanism is responsible for the formation of the basic clitoral structure, with the action of androgens limited to 'tuning' the system in both males and females, interfering with androgenic activity during fetal life should result in the convergence of both sexes on the form of the female spotted hyaena.

The aim of the present study was to maximize interference with androgenic actions on developing genital tissues. As there were no previous reports of anti-androgen treatment in hyaenas, several agents were used to identify an effective regimen. When administered to other pregnant mammals (for example, rats, mice, guinea pigs, rabbits and dogs), the androgen receptor blockers cyproterone acetate (Neumann et al., 1970) and flutamide (Neri et al., 1972; Neri, 1977) modify the external genitalia of male offspring, resulting in a penis of reduced size, with hypospadia, and a blind vaginal opening in the scrotal area. Although the present study was initiated with cyproterone acetate, subsequent pregnancies were treated with flutamide, which is preferable in terms of minimizing side effects (Ward and Ward, 1985). The progestational effects associated with cyproterone acetate administration interfere with parturition and make Caesarean sections a necessary accompaniment of such treatment (Neri, 1977).

In addition, $5 \alpha$-dihydrotestosterone has been implicated as the primary active metabolite of testosterone, promoting development of male external genitalia (Siiteri and Wilson, 1974; Wilson et al., 1981). In spotted hyaenas, there is a steady and proportional increase in maternal plasma testosterone and $5 \alpha$-dihydrotestosterone throughout the course of normal gestation (Licht et al., 1992). In the late stages of pregnancy, maternal concentrations approximate or even exceed those observed in adult males. Thus, $5 \alpha$-dihydrotestosterone may reach fetuses from the maternal circulation or via conversion of testosterone to $5 a$-dihydrotestosterone at target tissues by $5 \alpha$-reductase. The $5 \alpha$-reductase inhibitor, finasteride, was added to the flutamide treatment in a subset of pregnancies to block the conversion of testosterone to $5 \alpha$-dihydrotestosterone. Maternal blood was analysed for testosterone and $5 \alpha$-dihydrotestosterone to assess the efficacy of finasteride treatment.

Yalcinkaya et al. (1993) proposed that the high concentration of plasma $\Delta^{4}$-androstenedione observed in female spotted hyaenas was the result of follicular atresia during fetal life, due to exposure of the fetal ovary to testosterone. According to this line of speculation, preventing follicular atresia by blocking the effects of testosterone should result in more effective conversion of $\Delta^{4}$-androstenedione to oestrogen and, consequently, reduced $\Delta^{4}$-androstenedione secretion by the ovary during postnatal life. Consequently, plasma steroid concentrations were measured in developing infants.

\section{Materials and Methods}

\section{Animals}

The genital morphology of the offspring of eight experimental pregnancies, in which anti-androgens were delivered during gestation (Table 1), and of six untreated, control pregnancies, in spotted hyaenas (Crocuta crocuta) maintained at the Field 
Table 1. Anti-androgen treatment regimens for eight spotted hyaena pregnancies resulting in live births and stillbirths

\begin{tabular}{|c|c|c|c|c|c|}
\hline \multirow[b]{2}{*}{ Pregnancy } & \multicolumn{3}{|c|}{ Treatment } & \multicolumn{2}{|c|}{$\begin{array}{c}\text { Number of progeny } \\
\text { (sex) }\end{array}$} \\
\hline & Drug(s) & $\begin{array}{c}\text { Mean dose } \\
\left(\mathrm{mg} \mathrm{kg}^{-1} \text { day }^{-1}\right)\end{array}$ & $\begin{array}{l}\text { Duration } \\
\text { (days) }\end{array}$ & $\begin{array}{l}\text { Live } \\
\text { births }\end{array}$ & Stillbirths \\
\hline 1 & Cyproterone acetate $^{a}$ & 10.0 & 73 & $I(F)$ & $2(\mathrm{M}, \mathrm{M})^{+}$ \\
\hline 2 & Flutamide $^{\mathrm{b}}$ & 18.0 & 78 & $2(\mathrm{M}, \mathrm{M})$ & $I(\mathrm{M})$ \\
\hline \multirow[t]{2}{*}{$3^{*}$} & Flutamide & 22.8 & 75 & $2(\mathrm{~F}, \mathrm{~F})$ & $1(\mathrm{~F})$ \\
\hline & Finasteride $e^{c}$ & 0.56 & 48 & & \\
\hline \multirow[t]{2}{*}{4} & Flutamide & 23.1 & 72 & $1(\mathrm{M})$ & 0 \\
\hline & Finasteride & 0.60 & 72 & & \\
\hline \multirow[t]{2}{*}{5} & Flutamide & 24.0 & 89 & 0 & $2(\mathrm{M}, \mathrm{F})$ \\
\hline & Finasteride & 0.64 & 89 & & \\
\hline \multirow[t]{2}{*}{$6^{*}$} & Flutamide & 23.6 & 89 & $2(\mathrm{~F}, \mathrm{~F})$ & 0 \\
\hline & Finasteride & 0.61 & 89 & & \\
\hline \multirow[t]{2}{*}{7} & Flutamide & 19.7 & 100 & 0 & $1(F)^{+}$ \\
\hline & Finasteride & 0.51 & 100 & & \\
\hline \multirow[t]{2}{*}{8} & Flutamide & 24.6 & 98 & 0 & $2(F, F)$ \\
\hline & Finasteride & 0.98 & 98 & & \\
\hline
\end{tabular}

\footnotetext{
*Pregnancies involved the same mother.

${ }^{*}$ Animals were used for histological studies of the external and internal urogenital system, so their phallic measurements are not reported in this paper. However, these animals were examined for scrotal fusion and existence of a central urogenital canal traversing the phallus.

${ }^{a}$ Berlex Laboratories, Inc., Wayne, NJ.

${ }^{b}$ Schering Corporation, Kenilworth, NJ.

"Merck and Co., Inc., West Point, PA.
}

Station for Behavioral Research of the University of California, Berkeley, was studied. For heuristic purposes, the offspring of anti-androgen treated pregnancies are referred to as 'experimental' subjects, but note that there was no postnatal treatment. Data on genital development and steroid secretion were derived from eight infants of anti-androgen treated pregnancies (three males and five females; Table 1) and nine infants from control pregnancies (five males and four females), followed through the early juvenile period (1-6 months). Six stillborn neonates of anti-androgen treated pregnancies (two males and four females; Table 1 ) and five stillborn neonates from control pregnancies (two males and three females) were also examined. Within this sample of stillborn neonates, there were two pairs of mixed-sex twins. One pair was exposed prenatally to anti-androgens; the other was not. These four animals were a particularly useful group for comparison as they provided the best control available for sex and treatment variation.

\section{Anti-androgen treatment}

Agents, doses (corrected for body weight) and duration of drug administration for each anti-androgen treated pregnancy are presented (Table 1). In all but two of the anti-androgen treated pregnancies, a $5 \alpha$-reductase inhibitor (finasteride) was added to the daily regimen of drug administration. Antiandrogen treatment began after positive pregnancy tests and was continued throughout the remainder of the estimated 110 day gestational period (Kruuk, 1972). Drugs were administered orally in the daily diet and detailed records of actual consump- tion were kept (Table 1). As described below, all treatments had comparable effects on infant genital morphology.

\section{Genital appearance in developing and stillborn hyaenas}

Photographs were taken of the phallus (used here to refer to both male and female organs) and scrotal areas of all subjects. The presence or absence of papillae on the extruded organs of stillborn neonates was noted.

Erections displayed by young cubs engaged in meeting ceremonies were photographed, as described by Frank et al. (1990).

\section{Genital measurements in developing and stillborn hyaenas}

Genital development was monitored monthly (from 2-6 months) in anaesthetized infants (4-6 mg ketamine $\mathrm{kg}^{-1}$ and $1 \mathrm{mg}$ xylazine $\mathrm{kg}^{-1}, \mathrm{i} . \mathrm{m}$.). The penis or clitoris is normally retracted into the abdomen under anaesthesia, so all measures were taken after extrusion of the organ. In stillborn fetuses, all measurements were taken of the dissected, formalin-preserved genitals, as in an earlier study of dissected, fresh material from juvenile and adult hyaenas (Neaves $e t$ al., 1980). Data from live and stillborn cubs were handled separately. Although our measurement techniques differed slightly by subject pool, the basic measures were similar and were derived as follows:

The relaxed length of the urogenital meatus at the tip of the glans was measured, in both live and stillborn cubs, by placing a caliper on the glans and recording the length of the slit (Fig. Ia). 


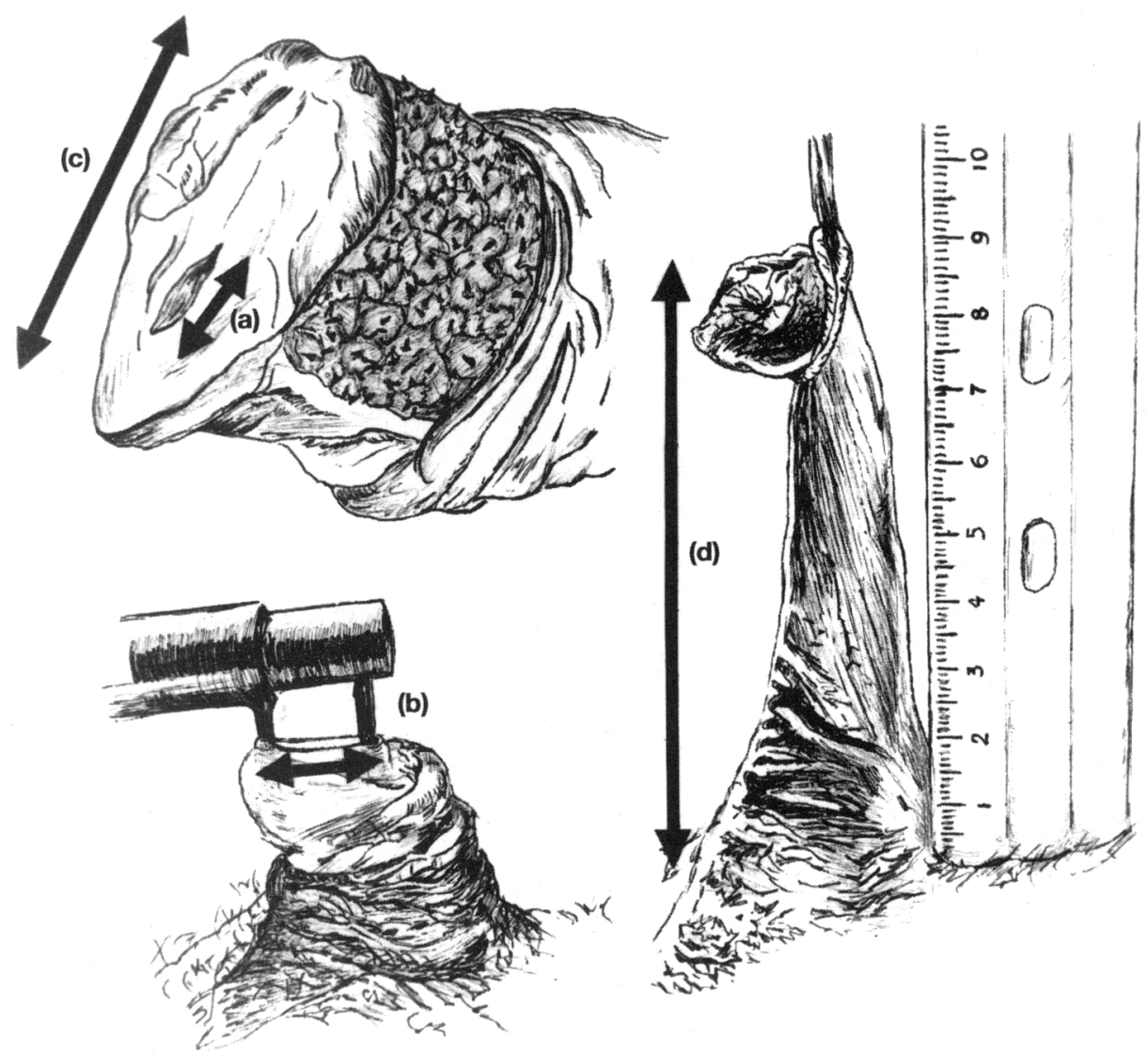

Fig. 1. Illustrations of a 'unisex' spotted hyaena phallus, with arrows showing the morphological measures used: (a) relaxed length of the urogenital meatus; (b) stretched length of the urogenital meatus; (c) diameter of the major axis of the glans; and (d) estimate of phallus length. Drawn by $\mathrm{C}$. Drea.

In developing cubs, the stretched length of the meatus was determined by first inserting a specially designed instrument, with one fixed and one mobile prong, into the meatus (Glickman et al., 1992b). The meatus was then placed under tension of $50 \mathrm{~g}$, as measured by a calibrated spring scale, and the length of the stretched opening was recorded (Fig. Ib). It was not possible to take a stretched meatus measurement from fixed tissue equivalent to that obtained in live subjects, so for stillborn cubs the circumference was estimated by insertion of a hypodermic needle into the urogenital opening. Successively larger needles were inserted until a snug fit, without pushing or stretching, was achieved. The meatus circumference was then calculated by multiplying the outer diameter of the 'best fit' needle by $\pi$.

The diameter of the major axis of the glans was measured, at its base, with a caliper (Fig. Ic).

The mid-shaft circumference was obtained, for stillborn cubs only, by tying a piece of silk thread around the middle of the shaft to a snug, but not pressured, fit. The thread was then cut and measured.

Phallus length in live cubs was measured by slipping a string 'noose' under the glans and pulling, at a right angle to the abdomen, to a tension of $150 \mathrm{~g}$ (Fig. 1d). This technique provides a reliable short-term measure, but as the phallus matures and increases in thickness, more tension is required to achieve full extension, and so the actual growth in length may have been underestimated by using a constant tension. In stillborn cubs, after retraction of the prepuce to expose the glans, the skinned phallus was suspended by the prepuce and the phallus length was measured from the point of attachment of the ischiocavernosus muscle on the dorsal aspect of the shaft to the tip of the glans.

\section{Plasma steroid measurements in pregnant adult and developing infant hyaenas}

Blood samples were obtained from the jugular vein of anaesthetized animals, 2-4 times from pregnant mothers, and each month from 1 to 6 months from their developing infants. Although sampling of mothers treated with cyproterone acetate or flutamide and finasteride was limited, samples were available from control and treated pregnancies for three subjects during the late stages of gestation; such paired comparisons are necessary because of large and consistent individual variations in pregnancy concentrations of steroids in these animals (Licht ef al., 1992). Testosterone and $5 \alpha$-dihydrotestosterone were separated by chromatography of extracted plasma on microcolumns of celite (Licht et al., 1992). The blood of developing cubs was assayed for circulating 
concentrations of testosterone, $\Delta^{4}$-androstenedione and oestradiol. Radioimmunoassays were performed for the measurement of testosterone, $\Delta^{4}$-androstenedione, $5 a$-dihydrotestosterone and oestradiol, as described by Licht et al. (1982, 1992).

\section{Statistical analyses}

It is not always possible to obtain phallic measurements before the third month of life, due to adhesion of the prepuce to the glans. Therefore, when available, data on phallic development for the second month are presented, but were excluded from statistical analyses. Initially, the four sextreatment groups (control females, control males, experimental females, experimental males) were cast in a two-way ANOVA with age as a repeated measure. On the basis of these analyses, a mean value for each morphological measure was calculated during months 3-6 and cast in a second set of ANOVAs, in which sex and treatment variables were separated to isolate effects. Analyses of phallic measurements in stillborn hyaenas and of blood hormone concentrations in developing infants (averaged across months 1-6) used one-way ANOVAs for the four sex-treatment groups. Post hoc, paired comparisons between groups used Scheffe's test.

\section{Results}

\section{Genital appearance in developing hyaenas}

All experimental males and females of anti-androgen treated mothers had a large, pendulous phallus and retained a normal scrotum or pseudoscrotum, respectively, with no evidence of any separate vaginal opening. However, there were effects of maternal anti-androgen treatment on infant phallic morphology, as detailed below. In addition, two of the three experimental males displayed a change in the shape of the glans when erect, assuming a rounded contour (Fig. 2b), indistinguishable from that of the erect clitoris of the female hyaena (Fig. 2a). The glans of the third male retained the normal angular configuration of control males (Fig. 2c), despite showing 'feminization' of the urogenital meatus, glans diameter, and phallic length (see below; Frank et al., 1990).

\section{Genital measurements in developing hyaenas}

Initial two-way ANOVAs revealed differences among sex and treatment groups in measures of relaxed and stretched meatus length, glans diameter, and phallic length $\left\langle F_{3,12}>7.3\right.$, $P<0.005)$. Significant effects of age were noted for all measures $\left(F_{3,12}>8.5, \quad P<0.001\right)$ except phallic length $(P>0.10)$. None of the interaction effects among age and sex-treatment group approached significance $(P>0.10)$. As detailed below, subsequent analyses revealed that the effects of fetal anti-androgen treatment were consistent: the penis was 'feminized' and the clitoris was further modified in the female direction.

Control female infants had a larger urogenital opening in the glans than did control males, both in the relaxed $\left(F_{1,12}=8.82\right.$, $P<0.02$; Fig. $3 a)$ and stretched $\left(F_{1,12}=24.3, \quad P<0.001\right.$;
Fig. 3b) states. Maternal anti-androgen treatment resulted in additional enlargement of the meatus in both male and female infants when measured in the relaxed $\left(F_{1,12}=9.04, P<0.02\right.$; Fig. 3a) and stretched $\left(F_{1,12}=33.96, P<0.001\right.$; Fig. $\left.3 \mathrm{~b}\right)$ states.

The diameter of the glans was larger in control females than control males $\left(F_{1,12}=11.96, P<0.01\right)$ and fetal anti-androgen treatment resulted in an increase in diameter in both sexes $\left(F_{1,12}=24.45, P<0.001\right.$; Fig. 3c). By contrast, the clitoris was shorter than the penis $\left(F_{1,12}=13.5, P<0.01\right)$ in control infants and treatment produced a decrease in both clitoral and penile length $\left(F_{1,12}=13.39, P<0.005\right.$; Fig. $\left.3 \mathrm{~d}\right)$. Neither interaction term was significant $(P>0.10)$.

\section{Genital appearance in stillborn hyaenas}

All stillborn hyaenas of anti-androgen treated mothers had a normal scrotum or pseudoscrotum, with no evidence of any external vaginal opening in either sex. Photographs of neonate phalluses show that the meatus of experimental males (Fig. 4c) was more similar in appearance (that is, position, size, and shape) to that of control females (Fig. 4e) than that of control males (Fig. 4a). Experimental males (Fig. 4d) and females (Fig. 4h) also showed alterations in the pattern of pigmentation, epithelial folds, and papillae that characterize the glans penis (Fig. 4b) and glans clitoris (Fig. 4f) of control animals. Some of these morphological differences are detailed below.

\section{Genital measurements in stillborn hyaenas}

Morphological data for the four 'test case' individuals from two mixed sex litters, as well as the averaged data obtained from the entire sample of stillborn neonates, are presented (Table 2). As in older, postnatal animals, the difference between the sexes was reduced in the experimental twins, with phallic measurements in males approaching female values.

The length and circumference of the relaxed urogenital meatus were smallest in control males and largest in experimental females, and this difference was of borderline significance for meatus length $(P=0.055$; Table 2$)$. The meatus circumference of experimental females was significantly larger than that of either control females or control males $(P \leq 0.05)$ and the meatus circumference of experimental males was larger than that of control males $(P<0.05)$. There were no differences between experimental males and experimental females in either measure $(P>0.10)$.

Glans diameter did not appear to differ as a function of sex, as there was no difference between experimental males and experimental females $(P<0.10)$; however, experimental females had a thicker glans than control females or control males $(P<0.05)$, and experimental males had a thicker glans than control males $(P<0.05$; Table 2).

Mid-shaft circumference was smailest in control males and substantially larger in all other stillborn neonates $(P<0.05$; Table 2). There were no significant differences between control and experimental females nor between experimental females and experimental males $(P>0.10)$. 

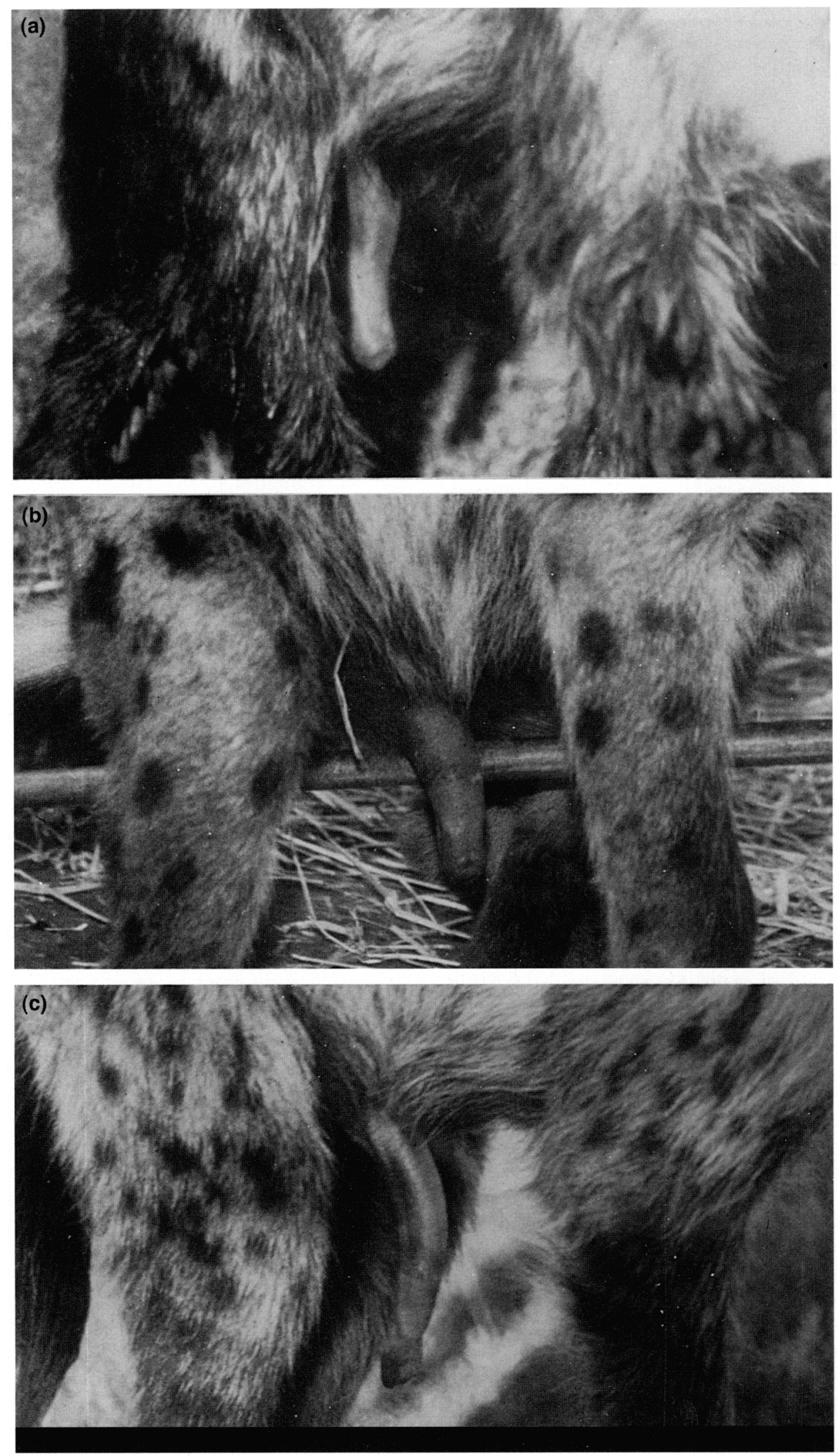

Fig. 2. Photographs of the erect phailus of infunt spotted hyaenas: a) control temale: (bi) experimental male, treated prenatally with anti-androgens, showing feminization of form; and ic control male. Note that the control male presents an angular contour of the glans and a constriction proximal to the glans. both of which are absent in the nomal female and the experimental male. 

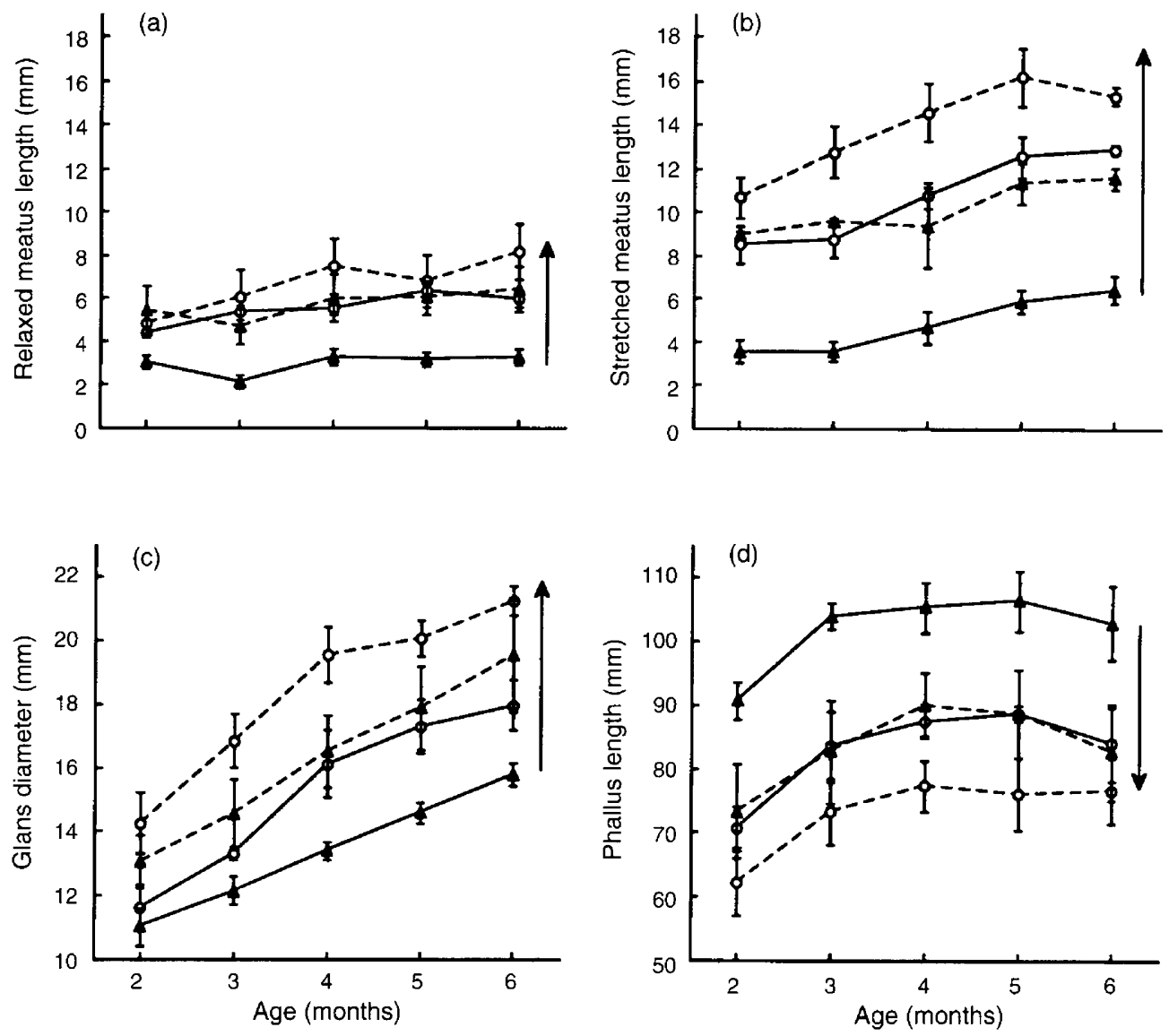

Fig. 3. Developmental changes in (a) relaxed meatus length, (b) stretched meatus length, (c) glans diameter, and (d) phallus length in infant spotted hyaenas. Male $(-\boldsymbol{\Delta}-)$ and female (-O-) infants of control pregnancies; male $(--\mathbf{\Delta}--)$ and female $(--O--)$ infants of pregnancies treated with anti-androgens. Values (mm) are reported as means \pm SEM and arrows indicate the direction of 'feminization'.

Phallus length was greater in control males than in any other stillborn neonates; however, no differences among the sex-treatment groups approached significance $(P>0.10$; Table 2).

\section{Plasma steroids in pregnant adult and developing infant hyaenas}

Paired comparisons of androgen concentrations during control and treated pregnancies for three adult hyaenas during the late stages of gestation are shown (Fig. 5). There was a consistent reduction in maternal plasma testosterone (Fig. 5a), as well as a larger proportional reduction in $5 a$-dihydrotestosterone (Fig. 5b) accompanying the combined treatment with flutamide and finasteride. The single subject treated with flutamide alone presented a testosterone concentration of $1.8 \mathrm{ng} \mathrm{ml}^{-1}$ and a $5 \alpha$-dihydrotestosterone concentration of $0.4 \mathrm{ng} \mathrm{ml}^{-1}$ at day 92 of gestation. Although there were no comparable samples from an untreated pregnancy for this subject, these values are within the normal ranges. No late pregnancy samples were available from the lone female treated with cyproterone acetate.

A one-way ANOVA of mean $\Delta^{4}$-androstenedione concentration in developing infants from 1 to 6 months revealed significant differences across the four sex-treatment groups
$\left(F_{3,12}=15.47, \quad P<0.001 ; \quad\right.$ Fig. 6a), with higher plasma $\Delta^{4}$-androstenedione in control females than in control males $(P<0.001)$ or in experimental females $(P<0.02)$. There were no differences in plasma $\Delta^{4}$-androstenedione between control males and experimental males $(P>0.10)$. Plasma testosterone did not vary across sex-treatment groups during the period studied $(P>0.10$; Fig. 6b). Oestradiol was undetectable in cubs before 6 months of age, within the limits of sensitivity of the assay $\left(30 \mathrm{pg} \mathrm{ml}^{-1}\right)$.

\section{Discussion}

The results of the present study show, for the first time, that naturally circulating androgens normally influence development of the penile clitoris of spotted hyaenas, as well as modifying postnatal hormone profiles. Moreover, the changes in clitoral-penile morphology in both female and male hyaenas are generally consistent with contemporary understanding of sexual differentiation, which accounts for differences between females and males of the same species in terms of higher concentrations of androgens in male fetuses (Jost, 1953; Wilson et al., 1981). Anti-androgen treatment of male hyaenas during fetal life 'feminized' their external genitalia, modifying the 

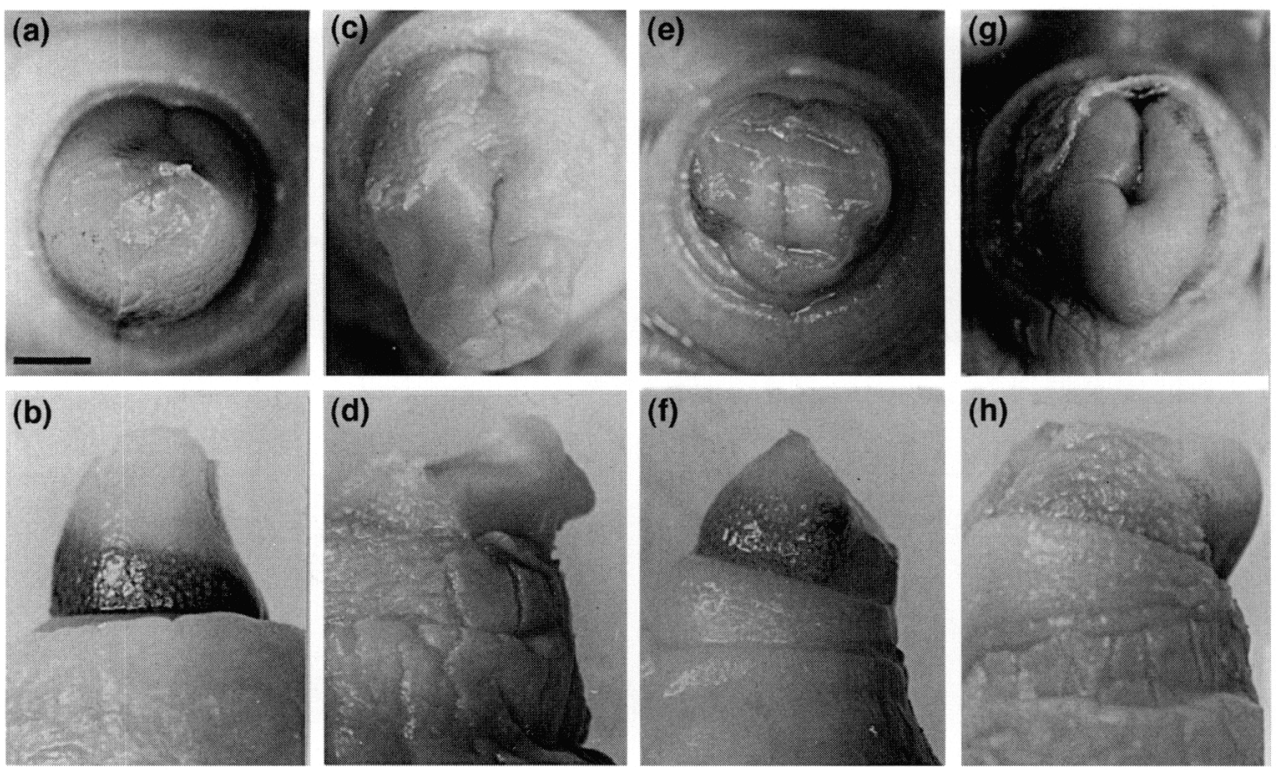

Fig. 4. The distal tip of the glans penis and glans clitoris of stillborn hyaenas from control and anti-androgen treated pregnancies, viewed from the front (top row) and side (bottom row) of the same specimens: $(a, b)$ control male; $(c, d)$ experimental male; $(e, f)$ control female; and $(g, h)$ experimental female. Scale bar represents $2 \mathrm{~mm}$.

Table 2. Effects of fetal anti-androgen treatment and sex on phallic morphology in stillborn spotted hyaenas

\begin{tabular}{|c|c|c|c|c|c|c|c|}
\hline \multirow[b]{2}{*}{$\begin{array}{l}\text { Treatment } \\
\text { group }\end{array}$} & \multirow[b]{2}{*}{ Sex } & \multirow[b]{2}{*}{$n$} & \multicolumn{5}{|c|}{ Morphological measures (mm) } \\
\hline & & & $\begin{array}{l}\text { Meatus } \\
\text { length }\end{array}$ & $\begin{array}{c}\text { Meatus } \\
\text { circumference }\end{array}$ & $\begin{array}{c}\text { Glans } \\
\text { diameter }\end{array}$ & $\begin{array}{l}\text { Shaft } \\
\text { circumference }\end{array}$ & $\begin{array}{l}\text { Phallic } \\
\text { length }\end{array}$ \\
\hline \multicolumn{8}{|c|}{ Individual values for two litters of mixed-sex twins } \\
\hline \multirow[t]{2}{*}{ Control } & Female & $I$ & 1.1 & 4.6 & 4.3 & 21.4 & 36.3 \\
\hline & Male & 1 & 0.9 & 2.8 & 4.6 & 16.4 & 48.6 \\
\hline \multirow[t]{2}{*}{ Experimental } & Female & 1 & 2.3 & 6.6 & 7.4 & 23.7 & 36.0 \\
\hline & Male & 1 & 2.1 & 5.2 & 7.6 & 24.9 & 40.3 \\
\hline \multicolumn{8}{|c|}{ Average values (mean \pm SEM) for all available litters } \\
\hline \multirow[t]{2}{*}{ Control } & Female & 3 & $1.5 \pm 0.3$ & $4.6 \pm 0.4$ & $4.3 \pm 0.2$ & $24.0 \pm 1.3$ & $38.4 \pm 2.1^{*}$ \\
\hline & Male & 2 & $1.0 \pm 0.1$ & $2.8 \pm 0.0$ & $3.7 \pm 0.8$ & $16.9 \pm 0.5$ & $40.5 \pm 8.1$ \\
\hline \multirow[t]{2}{*}{ Experimental } & Female & 4 & $2.4 \pm 0.3$ & $6.3 \pm 0.4$ & $6.7 \pm 0.4$ & $22.7 \pm 0.5$ & $33.6 \pm 1.4$ \\
\hline & Male & 2 & $2.1 \pm 0.0$ & $5.5 \pm 0.4$ & $6.8 \pm 0.8$ & $24.0 \pm 1.0$ & $35.7 \pm 4.7$ \\
\hline
\end{tabular}

* Only two measures were available.

appearance of the glans and producing a penis with the essential morphological characteristics of the female hyaena clitoris (that is, a shorter, thicker organ, with a large urogenital meatus and a glans with a rounded contour). The external genitalia of female hyaenas were also affected by fetal antiandrogen treatment, which further accentuated development in a feminine direction. Examination of stillborn infants indicated that fetal treatment with anti-androgens changes the phallus in a feminine direction and, as previously reported for dogs (Beach, 1970), alters the pattern of papillae on the glans. Thus, the basic sex differences in genital morphology are in place at birth and are not dependent on sex differences in postnatal steroid secretion. It is clear that urogenital development of both male and female spotted hyaena fetuses is normally influenced by circulating androgens, with placental circulation providing a major source of testosterone for female fetuses (Licht et al., 1992, 1998; Yalcinkaya et al., 1993).

Forger et al. (1996) have reported data on the genital musculature and nervous system of spotted hyaenas compatible with the observations regarding the form of the external genitalia in the present study. The bulbocavernosus muscle, which is involved in penile erection in other mammals and presumably influences male and female erections in the hyaena, is innervated by motor neurones in Onuf's nucleus of the sacral spinal cord. Sexual dimorphism, resulting from fetal androgen secretion, has been observed in the genital musculature and 

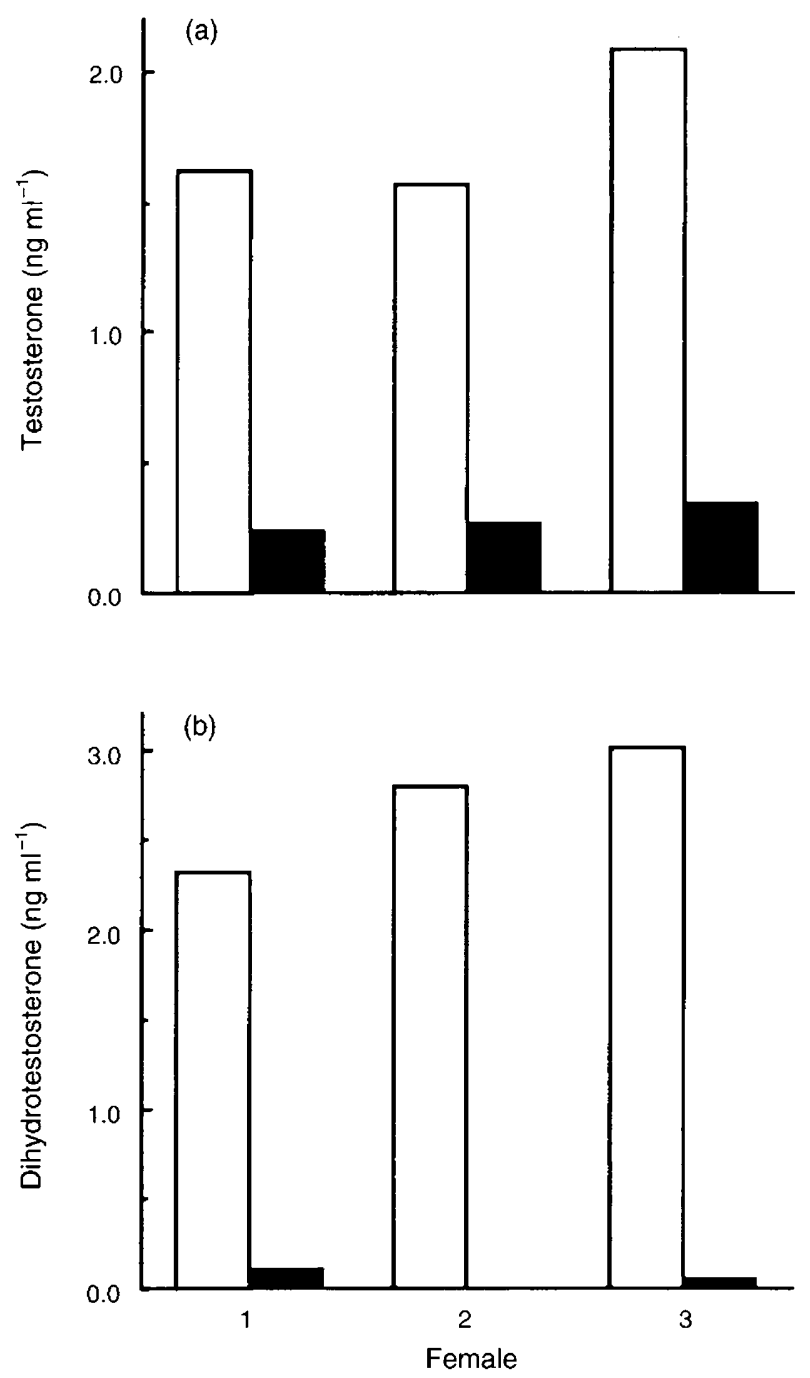

Fig. 5. Plasma concentrations (ng ml- ${ }^{-1}$ ) of (a) testosterone and (b) $5 a$-dihydrotestosterone in adult female spotted hyaenas (individuals 1 , 2 , and 3) during late gestation of a pregnancy treated with flutamide plus finasteride ( $\mathbf{\square}$ ) compared with values from comparable times in the preceding control pregnancy of each female $(\square)$. Blood samples were taken at day 93 and day 90 of gestation for female 1, at day 99 and day 104 of gestation for female 2, and at day 97 and day 92 of gestation for female 3 , during control and treated pregnancies, respectively.

associated spinal control mechanisms in a variety of mammals (Breedlove and Arnold, 1980; Forger and Breedlove, 1986). Despite the male-like clitoral erections that occur in female hyaenas, there were more motor neurones in Onuf's nucleus in males than in females, and this sex difference was associated with a larger bulbocavernosus muscle in males. Forger et al. (1996) used material from some of the same subjects that form the basis of the present study and found that prenatal antiandrogen treatment feminized both Onuf's nucleus and the bulbocavernosus muscle of neonatal male hyaenas, eliminating the sex difference normally present in these structures.

Despite the compatibility of our results with contemporary understanding of the role of androgens in accounting for structural differences between the sexes, a puzzle remains. At
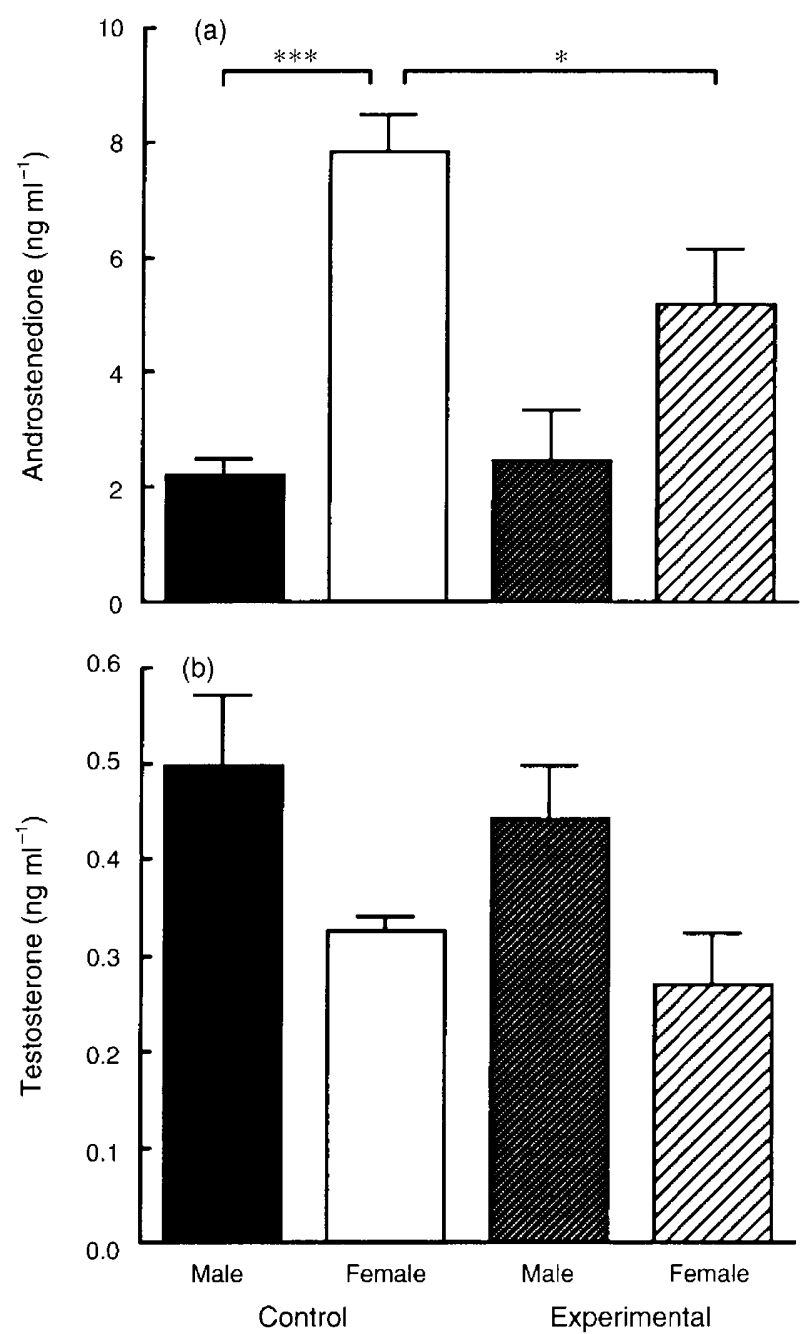

Fig. 6. Mean \pm SEM plasma concentrations (ng $\mathrm{ml}^{-\mathrm{l}}$ ) of (a) $\Delta^{4}$-androstenedione and (b) testosterone in spotted hyaenas at I-6 months of age. Male ( $\boldsymbol{\square}$ ) and female ( $\square$ ) infants of control pregnancies; male ( with anti-androgens. ${ }^{* * *} P<0.001, * P<0.02$.

the present time, the only mechanism known to produce a penis-like structure involves the influence of androgens on the genital tubercle during the fetal life of placental mammals. The clitoris and penis of spotted hyaenas remain remarkably 'masculine', despite the provision of anti-androgens and a $5 \alpha$-reductase inhibitor in quantities that block the formation and development of a penile structure in other species (Neumann et al., 1970; Neri et al., 1972; Neri, 1977). A decrease in androgen concentrations in the maternal circulation confirms that the anti-androgens were having an effect. The prenatal treatments in the present study produced neither males with extreme hypospadia nor females with an 'ordinary' mammalian clitoris and an external vaginal cleft in the scrotal region.

There are two possible explanations for these observations. First, it is conceivable that the treatments used did not block the androgenic activity underlying the formation of a penile structure from the genital tubercle (or a scrotal structure from the genital swellings), either because treatment was not 
initiated at a sufficiently early stage of gestation or because it produced inadequate effects on androgen receptors. The exact time of genital development in spotted hyaenas is not known, but in pigs, which have a gestation period of similar duration to that of hyaenas, formation of the penis and scrotum occurs between days 30 and 40 of gestation (Patten, 1948; Ford et al., 1980), weil after the point at which treatments were initiated in the present study. In pregnancies 7 and 8 (Table 1), treatment was initiated and maintained during the final 98-100 days of an approximately 110 day pregnancy, suggesting that flutamide and finasteride were circulating from days 10-12 of gestation. The formation of the penis or clitoris from the genital tubercle and the development of the scrotum or pseudoscrotum from the genital swellings would have had to occur at an unprecedentedly early stage of hyaena gestation to avoid the effects of our treatments; however, data presented in Licht et al. (1998) indicate that development of internal urogenital structures is proceeding at a pace approximating that of pigs. Nonetheless, in the singleton male and two female stillborn neonates that resulted from these pregnancies, the penis and clitoris were traversed in the usual manner by a central urogenital canal and there was no indication of impaired fusion of the scrotum or the vaginal labia.

As to the possibility that an insufficient number of the relevant receptors were blocked, the success of the treatments in 'feminizing' male hyaenas (that is, producing precisely the cluster of changes required to approximate the normal female configuration) strongly suggests that circulating concentrations of anti-androgen or finasteride, or both, similar to those inducing 'feminization' in other species, were achieved in developing hyaena fetuses in the present study. The fact that, thus far, no correlation between the magnitude of morphological effect and the variation in cyproterone acetate, flutamide, or flutamide-finasteride treatment has been observed also suggests that the maximum effective dose has been achieved. In addition, although no direct measure of $5 \alpha$-reductase or circulating $5 \alpha$-dihydrotestosterone in fetuses was made, the markedly decreased concentrations of maternal plasma $5 \alpha$-dihydrotestosterone argue for the efficacy of finasteride treatment in producing a general reduction in $5 \alpha$-reductase activity in spotted hyaenas.

The second possible explanation for the present results is that the treatments were effective in blocking androgenic activity but that there is an androgen-independent mechanism in spotted hyaenas that promotes the development of clitoralpenile tissues and the fusion of the genital swellings to form a scrotum, or pseudoscrotum. A second set of data, involving both the normal pace of growth and the effects of prepubertal gonadectomy, was analysed to explore the implications of this latter explanation, that is, to determine whether an androgenindependent mechanism promoted postnatal, as well as prenatal growth (Glickman et al., 1998). In this companion study, both penile and clitoral growth proceeded in near-normal fashion, with no evidence of either accelerated growth associated with pubertal secretion of steroids or any marked retardation of growth resulting from prepubertal gonadectomy.

As regards fetal androgens and postnatal steroid concentrations, a reduction in plasma $\Delta^{4}$-androstenedione was observed in the daughters of anti-androgen treated mothers, during the first 6 months of postnatal life. This finding supports the epigenetic hypothesis advanced by Yalcinkaya ef al. (1993) to account for the high concentrations of ovarian $\Delta^{4}$-androstenedione secretion in female spotted hyaenas of all ages (Glickman et al., 1992b). Yalcinkaya et al. (1993) suggested that placental conversion of maternal $\Delta^{4}$-androstenedione to testosterone bathes the female fetus in testosterone, which could permanently modify the structure of developing ovaries. Specifically, the number of follicular granulosa cells that synthesize oestradiol from $\Delta^{4}$-androstenedione would be reduced (Payne et al., 1956; Hillier and Ross, 1979; Hsueh et al., 1994), but $\Delta^{4}$-androstenedione-secreting thecal and interstitial cells would remain intact. Thus, a blockade of the placental androgens that normally circulate in the female fetus may increase the proportion of follicular tissue that survives in the ovary. Because follicular granulosa cells convert $\Delta^{4}$-androstenedione to oestradiol, ovarian secretion of oestradiol would be increased and secretion of $\Delta^{4}$-androstenedione decreased in females treated prenatally with anti-androgens. Additional studies of ovarian secretion and correlated histological comparisons of ovaries from normal and experimental females will be required to determine whether this is the actual mechanism.

Our current understanding of sexual differentiation provides an explanation for differences in the external genitalia between males and females of the same species, but it does not account for the basic morphology of the clitoris. There is extensive species variation in mammalian penile and clitoral morphology that is, at present, unexplained (Petter-Rousseaux, 1964; Short, 1979; Austin, 1984; Dahl and Nadler, 1992). For instance, the European mole (Talpa europea) has a peniform clitoris traversed by a urethra (Matthews, 1935), as do some lemuriform primates (Petter-Rousseaux, 1964; Ioannou, 1971). The results of the present study raise the possibility that the development of the hyaena clitoris and penis from the genital swellings and genital tubercle is driven by an androgen-independent mechanism. As noted previously, an alternative, androgen-independent mechanism has been described in marsupials (Renfree and Short, 1988). In tammar wallabies, development of the male marsupial penis is an androgen-dependent phenomenon; however, there are tissues of the abdomen that can develop into either a pouch or a scrotum. The formation of the male scrotum is an androgen-independent event involving a non-steroidal genetic mechanism, whereas development of a pouch is controlled by the presence of two $X$ chromosomes. It is conceivable that the development of the clitoris and pseudoscrotum in female spotted hyaenas, as well as the development of the penis and scrotum in the male, are also the result of an androgen-independent genetic event.

Androgen independence does not necessarily imply a complete absence of hormonal effects. Avila et al. (1996) have recently identified a single amino acid substitution in the hormone binding domain of the spotted hyaena that is not found in the striped hyaena (Hyaena hyaena). Female striped hyaenas do not exhibit the masculinized genitalia characteristic of spotted hyaenas. The functional significance of this amino acid substitution remains to be determined, but it is possible that the binding characteristics of the receptor have changed in a manner that either enhances the response to other steroids or limits the anti-androgenic actions of flutamide and cyproterone acetate. Limiting the action of anti-androgens would not, 
however, explain the lack of effect of prepubertal gonadectomy on penile growth and the relatively minor effects on clitoral growth.

The authors are indebted to the veterinary staff of the Office of Laboratory Animal Care on the Berkeley Campus, particularly D. Berger and D. DeNardo. The authors are also grateful to T. Wu for performing the radioimmunoassays and to C. Aguirre and S. Zippin for chromatographic separation that enabled measurement of $5 \alpha$-dihydrotestosterone concentration. This work was supported by Grant MH-39917 from the NIMH (to S. E. Glickman) and by National Research Service Award HD-07684 from the NIH (to C. M. Drea).

\section{References}

Arnold AP (1996) Genetically triggered sexual differentiation of brain and behavior Hormones and Behavior 30 495-505

Austin CR (1984) Evolution of the copulatory apparatus Bollettino di Zoologia $51249-269$

Avila DM, Wilson JD, Glickman SE and McPhaul MJ (1996) Sequence analysis of the gene encoding the androgen receptor (AR) of the spotted hyena Program of the 10th International Congress of Endocrinology $\mathrm{p}$ 188. San Francisco, CA

Beach FA (1970) Coital behavior in dogs: VI. Long-term effects of castration upon mating in the male Journal of Comparative and Physiological Psychology $\mathbf{7 0}$ $1-32$

Breedlove SM and Arnold AP (1980) Hormone accumulation in a sexually dimorphic motor nucleus of the rat spinal cord Science 210 564-566

Dahl JF and Nadler RD (1992) The external genitalia of female gibbons, Hylobates (H.) lar. The Anatomical Record 232 572-578

Ford JJ, Christenson RK and Maurer RR (1980) Serum testosterone concentrations in embryonic and fetal pigs during sexual differentiation Biology of Reproduction 23 583-587

Forger NG and Breedlove SM (1986) Sexual dimorphism in human and canine spinal cord: role of early androgen Proceedings of the National Academy of Sciences USA 83 7527-7531

Forger NG, Frank LG, Breedlove SM and Glickman SE (1996) Sexual dimorphism of perineal muscles and motorneurons in spotted hyenas Journal of Comparative Neurology 375 333-343

Frank LG, Glickman SE and Powch I (1990) Sexual dimorphism in the spotted hyaena (Crocuta crocuta) Journal of Zoology, London 221 308-313

Frank LG, Weldele ML and Glickman SE (1995) Masculinization costs in hyaenas Nature 377 584-585

Glickman SE, Frank LG, Davidson JM, Smith ER and Siiteri PK (1987) Androstenedione may organize or activate sex-reversed traits in female spotted hyaenas Proceedings of the National Academy of Sciences USA 84 3444-3447

Glickman SE, Frank LG, Licht P, Yalcinkaya TM, Siiteri PK and Davidson JM (1992a) Sexual differentiation of the female spotted hyena: one of nature's experiments Annals of the New York Academy of Sciences 662 135-159

Glickman SE, Frank LG, Pavgi S and Licht P (1992b) Hormonal correlates of 'masculinization' in female spotted hyaenas (Crocuta crocuta). 1. Infancy to sexual maturity Journal of Reproduction and Fertility 95 451-462

Glickman SE, Coscia EM, Frank LG, Licht P, Weldele ML and Drea CM (1998) Androgens and masculinization of genitalia in the spotted hyaena (Crocuta crocuta). 3. Effects of juvenile gonadectomy Journal of Reproduction and Fertility $113129-135$

Hillier SG and Ross GT (1979) Effects of exogenous testosterone on ovarian weight, follicular morphology and intraovarian progesterone concentration in estrogen-primed hypophysectomized immature female rats Biology of Reproduction $20261-268$

Hsueh AJW, Billig H and Tsafriri A (1994) Ovarian follicle atresia: a hormonally controlled apoptotic process Endocrine Reviews 15 707-724
Ioannou JM (1971) Female reproductive organs. In Comparative Reproduction of Nonhuman Primates pp 131-159 Ed. ESE Hafez. Charles C Thomas, Springfield, IL

Jost A (1953) Problems of fetal endocrinology: the gonadal and hypophyseal hormones Recent Progress in Hormone Research 8 379-418

Kruuk H (1972) The Spotted Hyena University of Chicago Press, Chicago

Licht P, Zucker I, Hubbard G and Boshes M (1982) Circannual rhythms of plasma testosterone and luteinizing hormone levels in golden-mantled ground squirrels (Spermophilus lateralis) Biology of Reproduction 27 411-418

Licht P, Frank LG, Pavgi S, Yalcinkaya TM, Siiteri PK and Glickman SE (1992) Hormonal correlates of 'masculinization' in female spotted hyaenas (Crocuta crocuta). 2. Maternal and fetal steroids Journal of Reproduction and Fertility 95 463-474

Licht P, Hayes T, Tsai P-S, Cuhna G, Kim H-S, Golbus M, Hayward S, Martin MC, Jaffe RB and Glickman SE (1998) Androgens and masculinization of genitalia in the female spotted hyaena (Crocuta crocuta). 1. Urogenital morphology and placental androgen production during fetal life journal of Reproduction and Fertility 113 105-116

Lindeque M, Skinner JD, Millar RP (1986) Adrenal and gonadal contribution to circulating androgens in spotted hyaenas (Crocuta crocuta) as revealed by LHRH, hCG and ACTH stimulation Journal of Reproduction and Fertility 78 211-217

Matthews LH (1935) The oestrous cycle and intersexuality in the female mole (Talpa europaea Linn.) Proceedings of the Zoological Society, London Series 2 347-383

Matthews LH (1939) Reproduction in the spotted hyena, Crocuta crocuta (Erxleben) Philosophical Transactions of Royal Society London Series B 230 1-78

Neaves WB, Griffin JE and Wilson JD (1980) Sexual dimorphism of the phallus in spotted hyaena (Crocuta crocuta) Journal of Reproduction and Fertility 59 509-513

Neri RO (1977) Studies on the biology and mechanism of action of nonsteroidal antiandrogens. In Androgens and Antiandrogens pp 179-189 Eds L Martini and M Motta. Raven Press, New York

Neri RO, Florance K, Koziol P and Van Cleave S (1972) A biological profile of a nonsteroidal antiandrogen, SCH 13521 (4'-nitro-3'trifluoromethylisobutyranilide) Endocrinology 91 427-437

Neumann F, von Berswordt-Wallrabe R, Elger W, Steinbeck H, Hahn JD and Kramer M (1970) Aspects of androgen-dependent events as studied by antiandrogens Recent Progress in Hormone Research 26 337-405

Patten BM (1948) Embryology of the Pig 3rd Edn. Blakiston Company, New York Payne RW, Hellbaum JN and Owens JN (1956) The effect of androgens on the ovaries and uterus of the estrogen treated hypophysectomized immature rat Endocrinology 59 306-316

Petter-Rousseaux A (1964) Reproductive physiology and behavior of the lemuroidea. In Evolutionary and Genetic Biology of Primates Vol. 2 pp 91-132 Ed. J Buettner-janusch. Academic Press, New York

Renfree MB and Short RV (1988) Sex determination in marsupials: evidence for a marsupial-eutherian dichotomy Philosophical Transactions of Royal Society London Series B 322 41-53

Short RV (1979) Sexual selection and its component parts, somatic and genital selection, as illustrated by man and the great apes Advances in the Study of Behavior 9 131-158

Siiteri PK and Wilson JD (1974) Testosterone formation and metabolism during male sexual differentiation in the human embryo Journal of Clinical Endocrinology and Metabolism 38 113-125

Ward IL and Ward OB (1985) Sexual behavior differentiation: effects of prenatal manipulations in rats. In Handbook of Behavioral Neurobiology, Vol 7 Reproduction pp 77-98 Eds N Adler, D Pfaff and RW Goy. Plenum Press, New York

Watson $M$ (1877) On the female generative organs of Hyaena crocuta. Proceedings of the Zoological Society, London 24 369-379

Wilson JD, George FW and Griffin JE (1981) The hormonal control of sexual development Science 211 1278-1284

Yalcinkaya TM, Siiteri PK, Vigne J-L, Licht P, Pavgi S, Frank LG and Glickman SE (1993) A mechanism for virilization of female spotted hyenas in utero. Science $2601929-1931$ 